\title{
Prostate cancer: To screen or not to screen? The question is complicated
}

W HETHER TO SCREEN for prostate cancer remains controversial due to the complexity of balancing the harms and benefits. Prostate cancer is the most common cancer in men and the second-leading cause of male cancer deaths. An estimated 192,000 men received the diagnosis during 2020, and 33,000 died from the disease. In contrast, lung cancer was diagnosed in about 116,000 men, and more than 72,000 died of it. ${ }^{1}$

See related article, page 14

The problem of prostate cancer overdiagnosis can be appreciated from autopsy studies. A review of 19 studies of autopsy-detected prostate cancer reported that in men age 70 to 79 who died of unrelated causes, $36 \%$ of US White men and $51 \%$ of US Black men were found to have malignant tumors in their prostate. ${ }^{2}$ Similarly, the Prostate Cancer Prevention Trial reported that biopsies reveal prostate cancer in $15 \%$ of men who had normal findings on digital rectal examination, normal prostate-specific antigen (PSA) levels, and no symptoms of the disease. ${ }^{3}$ Clearly, most cases of prostate cancer are not deadly, and yet tens of thousands of American men die of it each year.

Decisions about screening are difficult mainly due to the adverse effects of treatment, which include urinary incontinence and erectile dysfunction. Men undergoing radiation therapy are also at risk for rectal bleeding from radiation proctitis and for secondary (radiation-induced) cancers. Men who are treated and then develop a rising PSA withdoi:10.3949/ccjm.88a.20192 out evidence of metastatic disease may then be treated with hormonal therapy, which, in that setting, has known side effects and harms but no proven benefit. In other words, a screening test can lead to a cascade of treatment decisions and consequences. Balancing harms and benefits depends, in part, on the individual man's priorities and values; hence, shared decision-making is widely advocated.

In this issue of Cleveland Clinic Journal of Medicine (page 14) Sooriakumaran presents the argument in favor of screening based on the most recent data available and current practices for prostate cancer screening, diagnosis, and treatment. Several key facts deserve to be highlighted.

First, there is strong evidence of a diseasespecific mortality benefit from screening. The European Randomized Study of Screening for Prostate Cancer reported that with 16 years of follow-up, there was roughly a $20 \%$ reduction in the risk of death from prostate cancer (hazard ratio $0.80, P<.001) .{ }^{4}$ Based on the study results, 570 men would need to be invited to undergo screening in order to prevent 1 death from prostate cancer. Similarly, 1 death was prevented for every 18 cases diagnosed.

Second, decision-making has become more sophisticated and individualized about whom and when to biopsy, how to perform the biopsy, and, if cancer is diagnosed, which cancers need active treatment. These changes have mitigated the cascade from elevated PSA to biopsy to surgery or radiation therapy. The trend is toward reducing the burden of overdiagnosis by being more selective regard-
Decisions about screening are difficult mainly due to the side effects of treatment 
ing who gets biopsied and who gets treated.

It's also worth noting that worrisome changes in prostate cancer epidemiology have occurred since the use of PSA screening tests became less common after the US Preventive Services Task Force recommended against screening. ${ }^{5}$ With less screening, the diagnosis of clinically localized disease has declined while the incidence of locally advanced and metastatic disease has increased. ${ }^{6}$ For instance, between 2010 and 2016, the incidence of metastatic prostate cancer in men over age 75 increased $5 \%$ per year on average. ${ }^{7}$ The implication of the rising number of men with metastatic disease at diagnosis, given that metastatic prostate cancer is incurable, is that prostate cancer mortality may start to increase after decades of decline. Thus, while the problem of overdiagnosis has been reduced, the cost of that progress is likely to be more prostate cancer deaths.

The best path forward is not more screening or less screening, but rather to continue to develop better screening tests and algorithms for deciding who stands to benefit from early diagnosis and treatment. In the meantime, shared decision-making remains appropriate. Prostate cancer screening reduces prostate cancer deaths, but at a cost. Different men will weigh the harms and benefits differently.

\section{DISCLOSURES}

The author reports no relevant financial relationships which, in the context of his contributions, could be perceived as a potential conflict of interest.

\section{REFERENCES}

1. Howlader N, Noone AM, Krapcho M, et al (eds). SEER Cancer Statistics Review, 1975-2017, National Cancer Institute. Bethesda, MD, based on November 2019 SEER data submission, posted to the SEER web site April 2020. https://seer.cancer.gov/csr/1975_2017. Accessed December 15, 2020.

2. Jahn JL, Giovannucci EL, Stampfer MJ. The high prevalence of undiagnosed prostate cancer at autopsy: implications for epidemiology and treatment of prostate cancer in the prostate-specific antigen-era. Int J Cancer 2015; 137(12):2795-2802. doi:10.1002/ijc.29408

3. Thompson IM, Goodman PJ, Tangen CM, et al. The influence of finasteride on the development of prostate cancer. N Engl J Med 2003; 349(3):215-224. doi:10.1056/NEJMoa030660

4. Hugosson J, Roobol MJ, Mansson M, et al, ERSPC Investigators. A 16-yr follow-up of the European Randomized Study of Screening for Prostate
Cancer. Eur Urol 2019; 76(1):43-51. doi:10.1016/j.eururo.2019.02.009

5. Lee DJ, Mallin K, Graves AJ, et al. Recent changes in prostate cancer screening practices and epidemiology. J Urol 2017; 198(6):1230-1240. doi:10.1016/j.juro.2017.05.074

6. Sheng IY, Wei W, Chen Y-W, et al. Implications of the United States Preventive Services Task Force recommendations on prostate cancer stage migration. Clin Genitourin Cancer 2020 Jul 11; S1558-7673(20)30145-2. doi:10.1016/j.clgc.2020.06.006

7. Jemal A, Culp MB, Ma J, Islami F, Fedewa SA. Prostate cancer incidence 5 years after US Preventive Services Task Force recommendations against screening. J Natl Cancer Inst 2020 May 20;djaa068. doi:10.1093/ jnci/djaa068

Address: Timothy Gilligan, MD, Taussig Cancer Institute, CA-60, Cleveland Clinic, 9500 Euclid Avenue, Cleveland, OH 44195; gilligt@ccf.org 